\title{
Geotechnique
}

\section{Investigating the changing Deformation Mechanism beneath Shallow Foundations --Manuscript Draft--}

Manuscript Number:

Full Title:

Article Type:

Corresponding Author:

Corresponding Author's Institution:

Order of Authors:

Corresponding Author's Secondary
Institution:

Institution:

Order of Authors Secondary Information:

Manuscript Region of Origin:

Abstract:

\section{Suggested Reviewers:}

\section{Opposed Reviewers:}

\section{Additional Information:}

Question

\section{Response}

Have all the authors (and if necessary the Yes client) seen and approved the final article (Paper, Technical Note, Discussion contribution, Book review), and agreed submission to this journal? If your answer
14-P-226R2

Investigating the changing Deformation Mechanism beneath Shallow Foundations

General Paper

Srikanth Satyanarayana Chakrapani Madabhushi, MEng

University of Cambridge

Cambridge, UNITED KINGDOM

University of Cambridge

Srikanth Satyanarayana Chakrapani Madabhushi, MEng

Stuart Kenneth Haigh, MA MEng PhD (Cantab)

\section{UNITED KINGDOM}

The design of shallow foundations has traditionally used a mixture of plasticity based solutions to find the ultimate limit state and either a factor of safety on the plasticity solution or a linear elastic solution to attempt to design for the serviceability limit state. The serviceability limit state is intrinsically linked to the deformation mechanism that occurs beneath the shallow foundation in service. A better understanding of these soil movements can pave the way for more rational design approaches. In this paper, small scale experimental work is used to show that the deformation mechanism beneath strip and circular foundations continuously changes as the footing is displaced. The mechanisms observed at intermediate settlements, noted to be typical design points, are best described by a mixture of solutions. Linear mixes of idealised fields were analysed using an upper bound approach to determine the load displacement behaviour of each mix. The envelope of lowest upper bounds indicated that the optimal mix of fields changes depending on the footing settlement. At typical design points for shallow foundations mixtures dominated by ellipsoidal cavity expansion mechanisms were found to be optimal for both axisymmetric and plane strain cases. Comparison of theoretical and experimentally measured predictions indicated that using linear mixes of fields gives a good approximation to the true behaviour and may be used for settlement-based design approaches in the future.

Ashraf Osman, BSc MPhil PhD

Lecturer, Durham University ashraf.osman@durham.ac.uk

Dr Osman has previously investigated the deformation mechanisms beneath shallow foundations in the context of the extended mobilisable strength design framework.

Susan Gourvenec, BEng, PhD

Professor, University of Western Australia

Susan.Gourvenec@uwa.edu.au

Professor Gourvenec has conducted numerical analyses for both on and offshore shallow foundation systems. 
is "no" please explain the circumstances.

Please enter the total number of words in 5752 the main text only.

The main text of the paper should be as concise as possible. The word count of General Papers should not exceed 5000 words and for Technical Notes should not exceed 2000 words.

The word count of a submission excludes the abstract, list of notation, acknowledgements, references, tables and figure captions.

Discussions, Book Reviews, and Obituaries should be less than 1000 words.

Whilst Geotechnique reserves the right to publish papers of any length Authors should be aware that any submission for a General Paper that is significantly over the word limit will be subjected to preassessment and may be returned to the Authors for editing prior to being sent for review.

The word limit for Technical Notes will be strictly adhered to, and if over 2000 words, the submission will be considered as a General Paper.

Have you included a full notation list including definitions (and SI units of measurement where appropriate) for any mathematical terms and equations included in your paper?

Have you included a completed copyright Yes transfer form? This is required for all publications and can be found here.

Have you uploaded each of your figures separately and in high-resolution .tiff (ideal for photographs) or .eps files (best for line drawings)? This is required for all figures before your paper can be accepted. Our figure requirements can be found here.

Have you uploaded your tables in an editable Microsoft Word (.doc) format?

Have you included a separate list of all your figure and table captions?

Are your figures clear when printed in black and white? (For example, are plot lines distinguishable; are tints sequentially graded?) As this journal is printed in black and white, any figures that are unclear may be removed.

Are your references in Harvard style? Our Yes reference guidelines can be found here.

To ensure your paper is indexed correctly Bearing Capacity, Design, - and therefore as discoverable as possible - in our ICE Virtual Library, 
please choose up to 6 keywords from our

Keywords List. This can be found here.

We are unable to accept keywords that do not appear on this list.

Manuscript Classifications:

1-g modelling; FOUNDATIONS AND SOIL-STRUCTURE INTERACTION; PHYSICAL MODELLING; Settlement; SOILS MECHANICS \&amp; CONSTITUTIVE MODELS; Stiffness

Author Comments:

Dear Sir or Madam,

We would like to submit our manuscript titled "Investigating the changing Deformation Mechanism beneath Shallow Foundations " authored by myself and my co-author Dr Stuart K Haigh.

Kind regards,

Srikanth 


\section{Reply to Reviewers comments}

The authors are grateful for the additional comments made by the reviewers. They have endeavoured to take every comment into consideration and updated the manuscript in light of these comments.

1. Figures $3 b, 4 a, 4 c$ and 8 show small displacement vectors and contours. These figures may need some adjustments to ensure they are clear and readable at print scale in the final paper.

The thickness of the displacement vectors have been doubled in all the figures mentioned.

2. Introduction, line 28 - suggest defining abbreviation for serviceability limit state (SLS).

The abbreviation has been defined as suggested. The sentence now reads:

'Foundations are designed using a combination of calculations of Ultimate Limit State (ULS), protecting against failure, and Serviceability Limit State (SLS) to ensure acceptable levels of deformation'

3. Introduction, line 30 - suggest reviewing the wording 'Partial factors of around three...'. It is perhaps more accurate to refer to an 'overall /global factor of safety of around three'.

e.g. 'Partial factors are commonly used in geotechnical engineering practice to provide a global factor of safety of around three in order to guard against...'

The wording has been reviewed, and the sentence now reads:

'Partial factors are commonly used in geotechnical engineering practice to provide a global factor of safety of around three in order to guard against variability of the applied loads and material strengths and also to limit deformations.'

4. Experimental setup, para. 5. Reference to (White et al, 2002) should be (2003) as in the reference list.

The authors thanks the reviewer for spotting this. The necessary change has been made. 
- sigma(f), as used on y-axis in several figures

- delta, or delta(f), as used on x-axis in several figures and in equation 4

The single instance of delta(f) has been removed and sigma(f) and delta have been added to the notation list

6. Design example. This is now clearer for practitioners to apply the proposed method, after the revisions from the original draft. However, comments to illustrate the improved efficiency of the design based on the optimum displacement fields are no longer included. It would be useful to include some comments to illustrate this (e.g. reduction in footing diameter compared to a traditional ULS/SLS design), and to support the conclusions regarding the improved efficiency of the proposed method.

The authors thank the reviewer for this suggestion. The following text has been added to provide a comparison of the proposed method with a more traditional SLS calculation. The list of references and the notation list have been updated.

'This design can be compared with the result from the adjusted elasticity method, as suggested in Annex $F$ of Eurocode 7. The immediate settlement is given by equation 5 .

$w=\sigma_{f} D \frac{\left(1-v^{2}\right)}{E_{m}} I_{p}$

For the footing designed above, undrained conditions dictate $v=0.5$ and the influence factor $\mathrm{Ip}=1.8$ for this Poisson's ratio and a deep soil layer (Poulos and Davis, 1974). An estimate of the modulus of elasticity may be calculated using equation 6 (Vardanega and Bolton, 2011).

$E_{m}=\frac{S_{u}}{2 \times \gamma_{M=2}}$

The resulting modulus of $7143 \mathrm{kPa}$ treats the soil as linear elastic until half the undrained shear strength is mobilised. Hence, the adjusted elasticity method suggests a settlement of a rigid circular foundation of the order of $50 \mathrm{~mm}$. A more typical elastic modulus used in design calculations may be $40000 \mathrm{kPa}$ for London clay (i.e 400 times greater than the undrained shear strength), giving a settlement of approximately $9 \mathrm{~mm}$. In either case, the settlement predictions appear to be over predicted. Moreover, the advantage of the proposed method is not that it may produce more efficient solutions than codes of practice. Rather, the proposed method satisfies both the ULS and SLS without employing arbitrary factors of safety or requiring overly simplifying assumptions of the soil behaviour.' 


\title{
Investigating the changing Deformation Mechanism beneath Shallow Foundations
}

\author{
S. S. C. Madabhushi, BA MEng (Cantab), PhD Student, Department of Engineering, University of \\ Cambridge, sm854@cam.ac.uk
}

S. K. Haigh, MA MEng PhD (Cantab), Senior Lecturer, Department of Engineering, University of Cambridge, skh20@cam.ac.uk

\begin{abstract}
The design of shallow foundations has traditionally used a mixture of plasticity based solutions to find the ultimate limit state and either a factor of safety on the plasticity solution or a linear elastic solution to attempt to design for the serviceability limit state. The serviceability limit state is intrinsically linked to the deformation mechanism that occurs beneath the shallow foundation in service. A better understanding of these soil movements can pave the way for more rational design approaches. In this paper, small scale experimental work is used to show that the deformation mechanism beneath strip and circular foundations continuously changes as the footing is displaced. The mechanisms observed at intermediate settlements, noted to be typical design points, are best described by a mixture of solutions. Linear mixes of idealised fields were analysed using an upper bound approach to determine the load displacement behaviour of each mix. The envelope of lowest upper bounds indicated that the optimal mix of fields changes depending on the footing settlement. At typical design points for shallow foundations mixtures dominated by ellipsoidal cavity expansion mechanisms were found to be optimal for both axisymmetric and plane strain cases. Comparison of theoretical and experimentally measured predictions indicated that using linear mixes of fields gives a good approximation to the true behaviour and may be used for settlement-based design approaches in the future.
\end{abstract}

\section{INTRODUCTION}

Shallow foundation design primarily aims to spread the load of the structure over a sufficiently large area to reduce the stresses imposed on the soil to an acceptably safe level and to achieve an acceptably low settlement. Their widespread use in practice is due to their speed of design and relatively low design and construction costs.

Foundations are designed using a combination of calculations of Ultimate Limit State (ULS), protecting against failure, and Serviceability Limit State (SLS) to ensure acceptable levels of deformation. ULS calculations utilise plasticity theory to predict the maximum load which may be applied to the shallow foundation before 'failure'. Partial factors are commonly used in geotechnical engineering practice to provide a global factor of safety of around three in order to guard against variability of the applied loads and material strengths and also to limit deformations. Predictions of ground settlements can also be produced from elastic solutions, despite soil not being an elastic material. The aim of such a design approach is to limit the induced strains in the structure, which, owing to their brittle behaviour, is especially important for typical construction materials such as 
masonry or concrete. As excessive deformation always precedes failure (although this would not be revealed by an elastic calculation), it is the serviceability limit state that in general governs design.

In order to design shallow foundations directly from an SLS viewpoint, the applied loads must be linked with the soil movements, as the movement of the soil under the working loads govern the settlement of the superstructure in service. McMahon et al (2013a) conducted centrifuge experiments on circular shallow foundations on clay in undrained conditions and discovered that the soil movements, or deformation mechanism, change depending on the level of loading or settlement. Whilst at the ULS a Prandtl mechanism was an accurate representation of the soil movements, at the lower loads and settlements typical of SLS, the observed displacement of the soil was described as an 'ellipsoidal cavity expansion'. This mechanism is illustrated in Figure 1.

McMahon et al (2013a) introduced a framework for calculating the energy dissipated in the soil and used upper bound analyses to predict the load settlement behaviour of the shallow foundation. It was found that the 'optimal mechanism' (lowest work done to cause failure) switched as the settlement increased. It was also shown the upper bound based load settlement predictions matched well with the finite element analyses of Gourvenec and Randolph (2003) and Taiebat and Carter (2000). McMahon et al (2013a) proposed a single design line, independent of the undrained shear strength and soil stiffness, for predicting the undrained load settlement performance of a circular footing on uniform clay.

This paper provides further experimental evidence of the changing deformation mechanisms and aims to better link the observed deformation mechanisms with the footing displacement. Further analytical predictions are made using linear mixes of idealised fields, a method previously explored by Klar and Osman (2008). Optimising these mixes allows for lower upper bound predictions, tending towards the 'true behaviour'.

\section{EXPERIMENTAL SETUP}

Circular and strip footings were investigated in the work described here and hence both axisymmetric and plane-strain analyses were carried out. The models were constructed within a stiff Aluminium container with a Perspex window having internal dimensions $788 \times 200 \times 450 \mathrm{~mm}$. The model footings tested were made from Aluminium alloy, with the strip footing having a width of $50 \mathrm{~mm}$ and the circular footing consisting of a semicircular plate of diameter $50 \mathrm{~mm}$, symmetry being assumed on the plane of the window. These footings are sufficiently small to avoid any significant boundary effects from the sides of the testing tank assuming an elastic mechanism.

E-grade Kaolin clay was consolidated from slurry to avoid soil strength and stiffness anisotropy. A consolidometer was used that applied a uniform stress via a hydraulic piston with the stress being applied increased in increasing stages to allow the soil to gain strength and prevent extrusion of the slurry. The final consolidation stress was five times the nominal undrained shear strength, following the findings of Vardanega et al (2012). A summary of the nominal and measured undrained shear strengths for the tests carried out is shown in Table 1.

At the time of testing the model footings, the removal of the overburden pressure induced large suctions in the clay layer and hence a correspondingly large effective stress in the clay. The clay layer thus had approximately uniform effective stress, strength and stiffness throughout the clay layer, mitigating the usual inapplicability of small scale tests to field behaviour due to the non-linear, stress dependent nature of soils. Further, the uniform undrained shear strength and stiffness with depth 
better reflects the simplified analytical models than would centrifuge test data in which self-weight stresses increase substantially with depth.

Figure 2 shows a schematic and photograph of the experimental setup for the circular and strip footing configurations respectively. The footings were driven into the clay using a $1 \mathrm{D}$ actuator at a constant rate of displacement of $0.1 \mathrm{~mm} / \mathrm{s}$. A slower rate aids the visualisation process but was limited to try to ensure that the soil behaved in an approximately undrained fashion. As a check on this, the dimensionless loading rate proposed by Finnie and Randolph (1994) may be calculated. Originally defined for CPT tests as the product of the penetration rate and the cone diameter divided by the vertical coefficient of consolidation, Finnie and Randolph (1994) suggested a value of $<0.01$ represents totally drained conditions whilst a value $>20$ is completely undrained. For the previously defined loading rate of $0.1 \mathrm{~mm} / \mathrm{s}$, footings of width $50 \mathrm{~mm}$ on kaolin with a $c_{\mathrm{v}}$ value of approximately $0.5 \mathrm{~mm}^{2} / \mathrm{s}$ yields a value of 10 . Whilst some compromise was made on achieving 'true undrained compression' the dimensionless loading rate is close to the undrained limit of 20.

Visualisation of the deformation mechanism beneath the small scale foundations was achieved using Particle Image Velocimetry (PIV). (White et al, 2003). This software exploits the unique spatial variation of colour intensity across discrete 'patches' of soil to track the movement of these patches with time.

Following testing, a number of vane shear tests were conducted on the surface of the clay layers to provide rapid estimates of the undrained shear strength, the results of which are shown in Table 1. A number of samples were also taken from the clay layers for Triaxial testing. Unconfined UU compressive triaxial tests were conducted following the ASTM standard procedure. These tests were chosen as the stress state beneath the footing approximates triaxial compression with only small confining pressures being present during the small scale $1 \mathrm{~g}$ tests carried out. Table 2 indicates the results from these sets of tests. The shear strain at half the mobilised undrained shear strength, $\gamma_{M=2}$, and the empirical exponent, $b$, were both calculating following Vardanega and Bolton (2012). More details of the experiments reported in this paper can be found in Madabhushi (2014).

\section{EXPERIMENTAL LOAD SETTLEMENT BEHAVIOUR}

Load cells and a linearly variable differential transformer (LVDT), shown schematically in Figure 2a, were used to obtain the load settlement behaviour of the footings. The results from MSC2-a and MSC2-b are plotted in Figure 3a. The zero load, zero displacement point was chosen based on the first increase from the load cell baseline reading. Whilst this method was consistently employed for all data sets, it must be noted that a misalignment of the clay surface and footing or bedding errors at the clay surface are possible sources of error. This would especially affect the smaller displacement readings. For example, an error of $0.5 \mathrm{~mm}$ when estimating the point of zero displacement could move data on the origin to 1 on the logarithmic axis shown.

Figure 3 also shows GeoPIV visualisations of the deformation mechanisms, taken from the indicated levels of normalised settlement. Levels 'i', 'ii' and 'iii' represent very small, intermediate and large levels of normalised settlement respectively. Using the Matlab code originally written by Hanselman (2008) and edited by the authors, the steepest gradients in the GeoPIV fields were found. These were used to plot the soil 'streamlines' shown in Figure 3b. These streamlines represent the trajectories of soil particles and hence greatly clarify the overall deformation mechanisms. 
Examination of Figure $3 \mathrm{~b}$ reveals that for both axisymmetric and plane strain conditions the deformation mechanism clearly changes with displacement. At normalised displacement level ' $i$ ' the soil displaces mainly vertically downwards. A large volume of the soil experiences small displacements to accommodate the footing displacement. Such a deformation field is similar to the solution for an indentation made into an elastic material, as described by Boussinesq (1885). Differentiation of these fields and examination of the sum of the principal strains revealed there were small amounts of volumetric strain due to the compression of the soil - hence the lack of heave at the soil surface.

By displacement level 'iii' both footing types exhibit soil movements similar to those predicted by the Prandtl (1921) upper bound solution. Three rigid triangles can be observed, the central one moving vertically downwards and the left and right ones moving diagonally upwards at $45^{\circ}$. Between these regions the two slip fans can also be discerned, featuring many infinitesimal rigid elements moving along an arc. This type of 'plastic solution' features a smaller quantity of soil moving larger amounts to accommodate the displaced footing. The movements outside the predicted regions are due to the soil not being rigid-perfectly plastic, and hence suffering strains in the region bounding the plastic mechanism.

At displacement level 'ii', the development of horizontal movements is clear, though there is less soil moving towards the free surface and causing heaving than at displacement level 'iii'. The soil movements may be described as a mixture of the 'elastic' and 'plastic' solutions seen at displacement levels 'i' and 'iii' respectively.

The development of the deformation mechanisms, or rate of change of mechanisms differ between the strip and the circular footing. The deformation mechanisms determine the strains induced in the soil, and hence this differing rate of strain development is also reflected by the different load settlement behaviour recorded. For a given applied footing pressure, the strip footing undergoes larger amounts of settlement. The axisymmetric circular footing allows the soil to displace outwards in three dimensions. Conversely, the two dimensional plane strain conditions necessitate larger movements of the soil for a given footing displacement, implying larger shear strains and hence mobilising more of the soils' shear strength. Hence, the soil beneath the footings tends to a plastic solution quicker. This is also reflected by the experimentally obtained load settlement behaviour shown in Figure $3 \mathrm{a}$.

\section{THEORETICAL PREDICTIONS}

\section{Analysis Procedure}

The experimental results indicate that assuming a constant deformation mechanism, either elastic or plastic, will not lead to accurate settlement predictions at all levels of loading. Further, depending on the strain level, an incorrectly assumed deformation mechanism can lead to either dangerously low or inefficiently large predictions of the superstructure settlement, both of which are unacceptable for design.

McMahon et al (2013a) introduced a method of predicting the load settlement behaviour for any axisymmetric deformation mechanism, valid for a linear-elastic perfectly-plastic material. This approach was extended by McMahon et al (2014) to incorporate the non-linear stress-strain relation for clay proposed by Vardanega and Bolton (2012). The power law suggested, inferred from a database of triaxial tests on silts and clays is given by Equation 1. 
Table 2 shows appropriate values of $b$ and $\gamma_{M=2}$ based on the triaxial samples extracted from the clay beds after testing. The $b$ values of $0.75 \pm 0.1$ are at the upper end of the range proposed by Vardanega and Bolton (2012), but this might be expected based on the work of Vardanega et al (2012), who showed an increasing relationship between $b$ and OCR.

The shear strains are calculated from differentiating the deformation mechanism. The energy dissipated in mobilising these strains is calculated assuming a non-linear elastic perfectly-plastic model. The non-linear energy dissipated utilises equation 1 . The soil is assumed to behave perfectly plastically once the mobilised shear stress equals the undrained shear strength, or equivalently at the strain given in equation 2 for the values used in this analysis. The product of the principal strain and the undrained shear strength gives the perfectly plastic energy dissipation per unit volume.

$$
\gamma=\gamma_{M=2} \sqrt[b]{2}
$$

Finally, the sum of the energy dissipated is equated to the work done by the footing to achieve an upper bound estimate of the footing pressure required to cause the assumed deformation mechanism. Equation 3 illustrates this calculation, though a numerical integration was performed in practice. Full details of this analysis process can be found in McMahon et al (2013a) and McMahon et al (2014).

$$
N_{c}=\frac{1}{A_{f}}\left(\int_{\text {non-linear }} \frac{\partial W_{n}}{\partial \delta} d V+\int_{\text {plastic }} \frac{\partial W_{p}}{\partial \delta} d V\right)
$$

The underlying upper bound process was not changed in this paper. However, the calculation of strains and normalisation of the work done over the soil volume were modified to allow calculation of the load settlement behaviour for both plane strain and axisymmetric deformation mechanisms. The experimental results have shown that the deformation mechanism changes for both strain conditions. By constructing theoretical fields that reflect these changing deformation mechanisms upper bound predictions of the load settlement behaviour can be made. The only constraint is that the constructed deformation mechanism should obey the zero volumetric strain condition in order to be applicable for the design of shallow foundations on clay behaving in an undrained fashion.

Figure $3 \mathrm{~b}$ reveals that the deformation mechanism transitions from an elastic type mechanism to a plastic type mechanism as the footing settlement increases. The mechanism inserted into the energy calculations must hence reflect these features. One method to imitate these transitional fields is to linearly sum proportions of various deformation mechanisms and hence to calculate the energy dissipated by the resulting field, as described by Klar and Osman (2008) as part of the 'extended mobilisable strength design framework'. Puzrin and Randolph (2001) present a rigorous proof of how kinematically admissible strain fields can be combined to produce more optimal upper-bound predictions than those predicted by any of the fields on their own.

\section{Illustration of field mixing}

In Figure 4 an illustration of this field mixing approach for a circular foundation is given. The displacement field shown in Figure $4 \mathrm{a}$ is comprised of $90 \%$ of the field of a Prandtl type mechanism with distributed plastic strains, as originally defined by Osman and Bolton (2005) and hereafter referred to as the 'Osman field'. The other $10 \%$ comprises an elastic field, derived from an ABAQUS simulation of a footing on an elastic material with a Poisson ratio very close to 0.5 , hence conserving volume. The energy calculation assumes that the deformation mechanism remains geometrically 
similar but adjusts the strains to account for the increased footing displacement to predict the load displacement behaviour as shown in Figure $4 \mathrm{~b}$. A $b$ value of 0.6 was used in all the analyses presented here, representative of that of typical clays at large confining stresses, (Vardanega and Bolton, 2012).

The upper bound of the load displacement behaviour has not plateaued even at very high ratios of normalised settlement, indicating that the field is not optimal for large footing settlements. The energy surfaces in Figure $4 \mathrm{c}$ offer further clarity. The non-linear plastic work, dissipated at low shear strain values, and the perfectly plastic distributions are plotted. At low footing displacements (level ' $i$ ') only non-linear plastic work is dissipated. At the intermediate level 'ii' the core of the mechanism has strained sufficiently to cause perfectly plastic energy dissipation, whilst a shell of non-linear plastic strains surrounds this. Though the magnitudes of the non-linear work are comparatively smaller, in an axisymmetric mechanism the contribution of small strains at large radii can still significantly influence the load settlement prediction. By a settlement level of iii the perfectly plastic core has increased in size. However the remaining non-linear plastic shell illustrates why the selected mechanism is not able to reach the purely plastic solution, and hence does not plateau.

\section{Lowest Upper bounds from field mixing}

The experiments indicate that the 'optimum' deformation mechanism almost continually changes. By varying the proportions of the fields mixed, running the previous analysis for each field and selecting the lowest envelope of upper bound predictions, a better estimate of the settlement at a given loading can be constructed. Figure 5 shows this procedure for a strip footing, mixing the plane strain elastic solution with the Prandtl solution. It is important to note that unlike the previous deformation fields the Prandtl field features displacement discontinuities. In theory this should produce a shear band of infinite shear strains along these discontinuity boundaries. However, the computer based analysis infers the strains from the displacements, which are finitely spaced according to the mesh size. The resulting strains are hence very high rather than infinite and spread over a thickness comparable to the mesh size, rather than an infinitesimally thin boundary.

The result of this approximation is the predicted load displacement behaviour in Figure 5a is not 'rigid perfectly plastic'. Interestingly, the effect of smoother strains around the discontinuity boundaries is to produce more optimal upper bound estimates at low settlements - the bearing capacity factor predicted is below 5.14. The trade-off is at large settlements the predicted bearing capacity factor plateaus at 5.2 rather than 5.14 - without infinite shear strains the known optimum can't be reached. The finer the mesh used for the displacement field, the higher the bearing capacity factor at low settlements but the closer the plateau to 5.14. The mesh presented represents a compromise between accuracy and computation time. Despite these subtleties, the deformation field modelled will hereafter be referred to for brevity as the Prandtl field.

The optimal proportion of the Prandtl field is shown in Figure 5b. The optimal proportion of the Prandtl field at low settlements is zero and hence the mesh effects discussed above have no impact on the lowest upper bound found. After the $100 \%$ elastic field ceases to be optimal, the proportion of the Prandtl field mixed to make the idealised field varies continually with settlement. This matches the experimental observations that the deformation mechanism is changing with the footing settlement. Further, the smoothly increasing proportion of the Prandtl field required indicates that the deformation mechanism is also transitioning smoothly. This suggests the approach of linearly mixing the deformation fields is superior to evaluating the load displacement behaviour of individual 'types' of field as previously studied. 
Figure 6 presents the results for a similar technique applied to circular foundations. For clarity, only 'ellipsoidal cavity expansion' deformation mechanism. In McMahon et al (2014) it was found that such a mechanism is optimal compared to the pure elastic solution or the Osman solution in the intermediate settlement ranges. Hence, it was decided to mix these three fields in varying proportions to investigate the interplay. For the cavity expansion mechanism, the transition of the soil displacement from being normal to ellipsoids to normal to hemispheres occurs at twice the footing depth. This follows from the results found by McMahon et al (2013a).

The results in Figure 6 agree well with previous research whilst providing some new insights. Large proportions of either the elastic mechanism or the cavity expansion at high footing settlements result in fields that dissipate too much energy to be optimal. This results in the growing proportion of the Osman field, similar to that seen for the Prandtl field in Figure 5. At very low settlements, McMahon et al (2014) found that the purely elastic solution is optimal until a switch to the pure cavity expansion mechanism at intermediate settlements. The research presented in this paper shows that a mixture of the elastic and the cavity expansion solutions, in approximately equal quantities, is more optimal even at very low settlements. At intermediate settlements the proportion of the elastic field falls as the cavity expansion mechanism reaches a peak optimal proportion, before falling away as the Osman field begins to dominate. These results justify the findings by McMahon et al (2014) that a cavity expansion mechanism produces optimal deformation mechanisms at intermediate settlements. However, it is also clear that at all the settlement ranges shown the mixing of fields produces more optimal upper bound estimates than any one of the individual fields. Observing the superposition of all load settlement predictions, as shown in Figure 5a for the strip footing, indicated the optimisation offered by mixing fields was greatest at intermediate settlements. This will be further discussed later in the context of a design example.

Following a procedure similar to that detailed by McMahon et al (2013a), the ellipsoidal cavity expansion solution, valid for plane strain conditions, was determined. Ellipses which transition to semicircles at a depth of 2 footing diameters were constructed, and used to find the displacements by utilising equation 4. The surface area of the ellipses was found using the Ramanjun (1914) approximation.

$$
w=\frac{A_{f}}{A_{e}} \delta
$$

Whilst this conserves volume across elliptical regions, it potentially allows for local compression or extension within these regions. However, examination of the strains revealed these did not occur in practice, except at the footing edge where purely vertical and purely horizontal displacements are adjacent. McMahon et al (2013a) found that the effect of this error on the load-settlement prediction was negligible.

Using the plane strain ellipsoidal cavity expansion solution, a three way mix with the plane strain elastic and Prandtl solution was conducted. The trend of optimal proportions shown in Figure 7 is in strong agreement with Figure 8. At low settlements a mixture of the elastic and cavity expansion solution dominates. The optimal proportion of the cavity expansion peaks at intermediate settlements, then falls away as the optimal proportion of the Prandtl solution increases. The plane strain cavity expansion peak is at larger normalised settlements than the axisymmetric equivalent. This is mainly due to using the Prandtl solution which does not have distributed plastic strains, unlike the axiysmmetric Osman solution. 
Comparison between the optimal fields generated by the analysis shown in Figure 6 and the experimentally observed results from test MSC2-b is offered by Figure 8. The streamlines of soil movement are also shown, calculated as described earlier for Figure $3 \mathrm{~b}$. The fields shown are from three levels of normalised settlement of the circular footing. The soil deformations that occur, i.e. the 'real solutions', are the displacements that result in the least energy dissipation. Hence, the closer the agreement between the theoretical and observed fields the closer the lowest upper bound calculated will be to the real solution. Figure 8 shows that in general there is good agreement between the predicted optimal fields and observed fields. Both sets show the transition from mechanisms involving small displacements of large volumes of soil to mechanisms where it is a smaller volume of soil, mainly near the surface, that displaces larger amounts. However, the observed fields do exhibit more horizontal displacements at lower normalised settlements. Earlier examination of the volumetric strains derived from the experimental results revealed the clay near the surface was experiencing some consolidation. It is possible this led to mechanisms with more near surface displacements becoming optimal, compared to the theoretical predictions which maintain perfectly undrained conditions throughout. In any case one would expect the GeoPIV to be more accurate in determining the fields at larger footing displacement, owing to the larger signal to noise ratio. Figure 8 also suggests the usefulness of mixing the fields. Even at the largest footing settlement, it is clear that there is some soil movement outside the Osman solution, justifying the mixing with the cavity expansion and elastic solution used in the theoretical prediction.

\section{Comparison of experimental and analytical results}

Having applied both experimental and analytical techniques to the problem of the changing deformation mechanism beneath shallow foundations, it is prudent to conclude with the implications for the practical aspects of design of shallow foundations. We consider the experimentally obtained load settlement behaviour to be our 'correct' solution. Figures $9 a$ and $9 b$ illustrate the closeness of the upper bound calculations to the correct solutions, for the circular and strip foundation respectively.

Observing Figure 9a reveals that the pure elastic, cavity expansion and Osman solutions transition from being the lowest upper-bound at very low, intermediate and large footing settlements respectively. However, the upper bound predicted by the optimal mixes of these three fields is consistently lower, and hence represents a better possible design curve. In general, the same can be said of Figure 9b; the optimal mixes of the pure fields is superior to using any single field across the entire settlement range. In Figure $9 \mathrm{~b}$ the intersection of the experimental data with the lowest upper bound is not theoretically expected. The sensitivity of the experimental data to the initial selection of the 'zero load, zero displacement' point is one possible cause of this result. Alternatively, small amounts of drainage of the clay at large footing displacements could also be responsible.

The key point is that the discrepancy between a single field or the optimal mixes and the "true behaviour' varies depending on the level of settlement. For example, at very low settlements a designer using only the elastic or cavity expansion solution would make a reasonably accurate prediction of the allowable footing pressure to cause a given settlement. However, typical design points for shallow foundations utilise a factor of safety between 2 and 3. At these working ranges accurate settlement predictions are more sensitive to the assumed deformation mechanism.

Figure 10 illustrates the proposed design curves for both circular and strip footings, based on the theoretically obtained lowest upper bounds. As an example of using these results in design, one may 
consider the design of a circular shallow foundation on London Clay. The designer may be required to select an appropriate diameter for a given load within a maximum settlement. Let us consider a specified load of $200 \mathrm{kN}$ and an allowable short term undrained settlement of $5 \mathrm{~mm}$. The undrained shear strength may be taken as $100 \mathrm{kPa}$ and Vardanega and Bolton (2011) suggest an average value of $\gamma_{\mathrm{M}=2}=0.0070$ for London clay. The following steps illustrate how the design process may commence.

1. Begin by selecting an approximate ratio of allowable footing pressure to undrained shear strength, (for example using a factor of safety of $2, \sigma_{\mathrm{f}} / \mathrm{s}_{\mathrm{u}}=3$ ).

2. From a standard design calculation, estimate the foundation diameter. (In our case $0.92 \mathrm{~m}$ )

3. Using Figure 10 read across from the selected footing pressure on the y-axis to the circular footing design curve to find the normalised settlement. (In our case this implies a normalised settlement of 0.9 ).

4. For a diameter of $0.92 \mathrm{~m}$ from step 2 and a value of $\gamma_{\mathrm{M}=2}=0.0070$ this footing would settle by $5.8 \mathrm{~mm}$

5. As the settlement is larger than permitted, the process must be repeated with a lower allowable footing pressure selected. This iterative process can be continued until the required settlement is obtained.

6. For example, it is found that a footing pressure to undrained shear strength ratio of 2.8 implies a diameter of $0.95 \mathrm{~m}$ with a settlement of $5.0 \mathrm{~mm}$

It should be noted that the choice of load displacement behaviour in step 3 is quite critical as the estimates are upper bounds. Applying a calculated footing pressure based on an incorrectly selected deformation mechanism could lead to unexpectedly large settlements in practice.

This design can be compared with the result from the adjusted elasticity method, as suggested in Annex F of Eurocode 7. The immediate settlement is given by equation 5 .

$$
w=\sigma_{f} D \frac{\left(1-v^{2}\right)}{E_{m}} I_{p}
$$

For the footing designed above, undrained conditions dictate $v=0.5$ and the influence factor $I_{p}=1.8$ for this Poisson's ratio and a deep soil layer (Poulos and Davis, 1974). An estimate of the modulus of elasticity may be calculated using equation 6 (Vardanega and Bolton, 2011).

$$
E_{m}=\frac{S_{u}}{2 \times \gamma_{M=2}}
$$

The resulting modulus of $7143 \mathrm{kPa}$ treats the soil as linear elastic until half the undrained shear strength is mobilised. Hence, the adjusted elasticity method suggests a settlement of a rigid circular foundation of the order of $50 \mathrm{~mm}$. A more typical elastic modulus used in design calculations may be $40000 \mathrm{kPa}$ for London clay (i.e 400 times greater than the undrained shear strength), giving a settlement of approximately $9 \mathrm{~mm}$. In either case, the settlement predictions appear to be over predicted. Moreover, the advantage of the proposed method is not that it may produce more efficient solutions than codes of practice. Rather, the proposed method satisfies both the ULS and SLS without employing arbitrary factors of safety or requiring overly simplifying assumptions of the soil behaviour.

\section{CONCLUSIONS}

The globally widespread use of shallow foundations necessitates accurate predictions of their behaviour to ensure safety, performance and efficient design. A rationalised design approach that does 
not resort to arbitrary factors of safety provides the designer with greater control of their design point, knowing exactly how far the chosen shallow foundation design is from the limit states. This paper has illustrated that utilising a deformation mechanism that is allowed to smoothly vary between elastic, Prandtl and Cavity expansion mechanisms allows more optimal design to be carried out than by utilising any of the mechanisms in isolation. The paper has also illustrated that small-scale test data on plane-strain and axisymmetric shallow foundations yield load-displacement data and deformation mechanisms that validates this analysis.

Use of the procedures developed by McMahon et al (2013) and further refined here allows shallow foundation design for serviceability to be carried out directly, rather than by using arbitrary Factors of Safety and hence leads to both safe and more efficient performance-based design.

\section{REFERENCES}

Boussinesq, J. (1885). Application des potentiels a l'etude de l'equilibre et due movement des solids elastiques. Gauthier Villars, Paris

Finnie, I. M. S. and Randolph, M. F. (1994). Punch-through and liquefaction induced failure of shallow foundations on calcareous sediments. Proc. Int. Conf. on Behavior of Offshore Structures, Boston, USA

Gourvenec, S. and Randolph, M. F. (2003). Effect of strength non-homogeneity on the shape and failure envelopes for combined loading of strip and circular foundations on clay. Géotechnique, 53(6), pp. $575-586$

Hanselman, D.C. (2008). Improved 2D Streamlines. http://www.mathworks.co.uk/matlabcentral/ fileexchange/38860-improved-2dstreamlines/content/mmstream2.m. MATLAB Central File Exchange. Accessed on 03/04/2014

Klar, A., and Osman, A. S. (2008). Load - displacement solutions for piles and shallow foundations based on deformation fields and energy conservation. Géotechnique, 58(7), pp. 581-589

Madabhushi, S. S. C. (2014). Investigating the Deformation Mechanisms beneath Shallow Foundations, MEng Dissertation, University of Cambridge, UK

McMahon, B. T., Haigh, S. K., and Bolton, M. D. (2013a). Cavity Expansion model for the bearing capacity and settlement of circular shallow foundations on clay, Géotechnique 63(9), pp. 746-752.

McMahon, B. T., Haigh, S. K., and Bolton, M. D. (2013b). Optimal displacement mechanisms beneath shallow foundations on linear-elastic perfectly plastic soil, Géotechnique 63(16), pp. 14471450 . 
McMahon, B.T., Haigh, S.K. and Bolton, M.D. (2014). Bearing capacity and settlement of circular shallow foundations using a non-linear constitutive relationship, Canadian Geotechnical Journal 51(9), pp. 995-1003

Osman, A. S. and Bolton, M. D. (2005). Simple plasticity-based prediction of the undrained settlement of shallow circular foundations on clay. Géotechnique 55(6), pp. 435-447.

Poulos, H. G. and Davis, E. H. (1974). Elastic Solutions for Soil and Rock Mechanics. John Wiley \& Sons, New York.

Prandtl, L. (1921). Uber die eindringungsfestigkeit plastischer baustoe und die festigkeit von schneiden. Zeitschrift fur Angewandte Mathematik und Mechanik, 1, pp. 15-20.

Puzrin, A. M and Randolph, M. F. (2001). On the superposition of plastically dissipated work in upper bound limit analysis, Proceedings of the Royal Society of London Series a-Mathematical Physical and Engineering Sciences, vol. 457(2007), pp. 567 - 586

Ramanujan, S. (1914). Modular Equations and Approximations to $\pi$. Quarterly Journal of Pure Applied Mathematics, 45, pp 350-372.

Taiebat, H. A. and Carter, J. P. (2000). Numerical studies of the bearing capacity of shallow foundations on cohesive soil subjected to combined loading. Géotechnique, 50(4), pp. 409-418.

Vardanega, P. J. and Bolton, M. D. (2011). Predicted shear strength mobilization of London clay. Proc. 15th Euro. Conf. Soil Mech. and Geotech. Engng, Athens, 12-15 September 2011. IOS Press, vol. 1, pp. 487-492.

Vardanega, P. J. and Bolton, M. D. (2012). Strength mobilization in clays and silts. Canadian Geotechnical Journal 48(10), pp. 1485-1503.

Vardanega, P. J, Lau, B.H, Lam, S, Haigh, S. K, Madabhushi, S. P. G, and Bolton, M. D. (2012). Laboratory measurement of strength mobilisation in kaolin: link to stress history. Géotechnique letters, Vol. 2, pp. 9-15.

White, D. J., Take, W. A. and Bolton, M. D. (2003). Soil deformation measurement using particle image velocimetry (PIV) and photogrammetry. Géotechnique, 53(7), pp. 619-631. 


\section{NOTATION}

\section{Roman}

$A_{e} \quad$ surface area of ellipse

$A_{f} \quad$ surface area of footing

$b \quad$ empirical exponent

$\mathrm{c}_{\mathrm{v}} \quad$ coefficient of consolidation

$\mathrm{E}_{\mathrm{m}} \quad$ modulus of elasticity

$N_{c} \quad$ bearing capacity factor

$s_{u} \quad$ undrained shear strength

UU unconsolidated-undrained

$w \quad$ normal displacement

$W_{n} \quad$ non-linear work

$W_{p} \quad$ perfectly plastic work

\section{Greek}

$\tau \quad$ shear stress

$\sigma_{\mathrm{f}} \quad$ footing pressure

$\delta \quad$ footing settlement/displacement

$\gamma \quad$ shear strain

$\gamma_{M=2} \quad$ shear strain at half the mobilised shear strength 


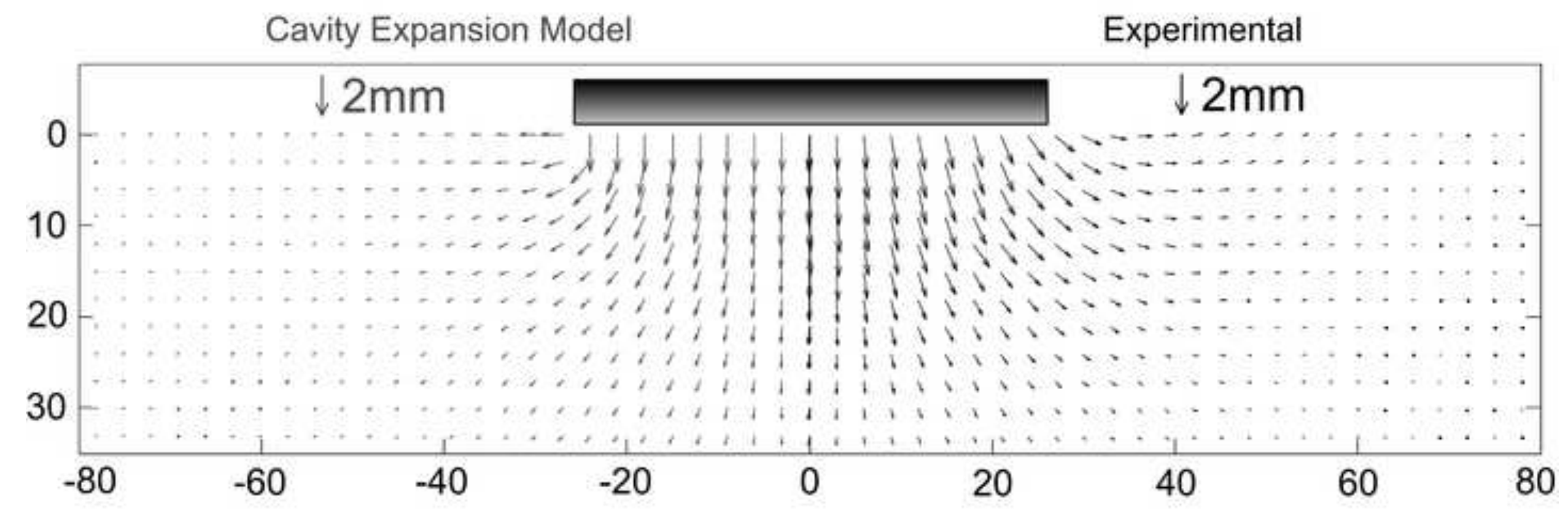




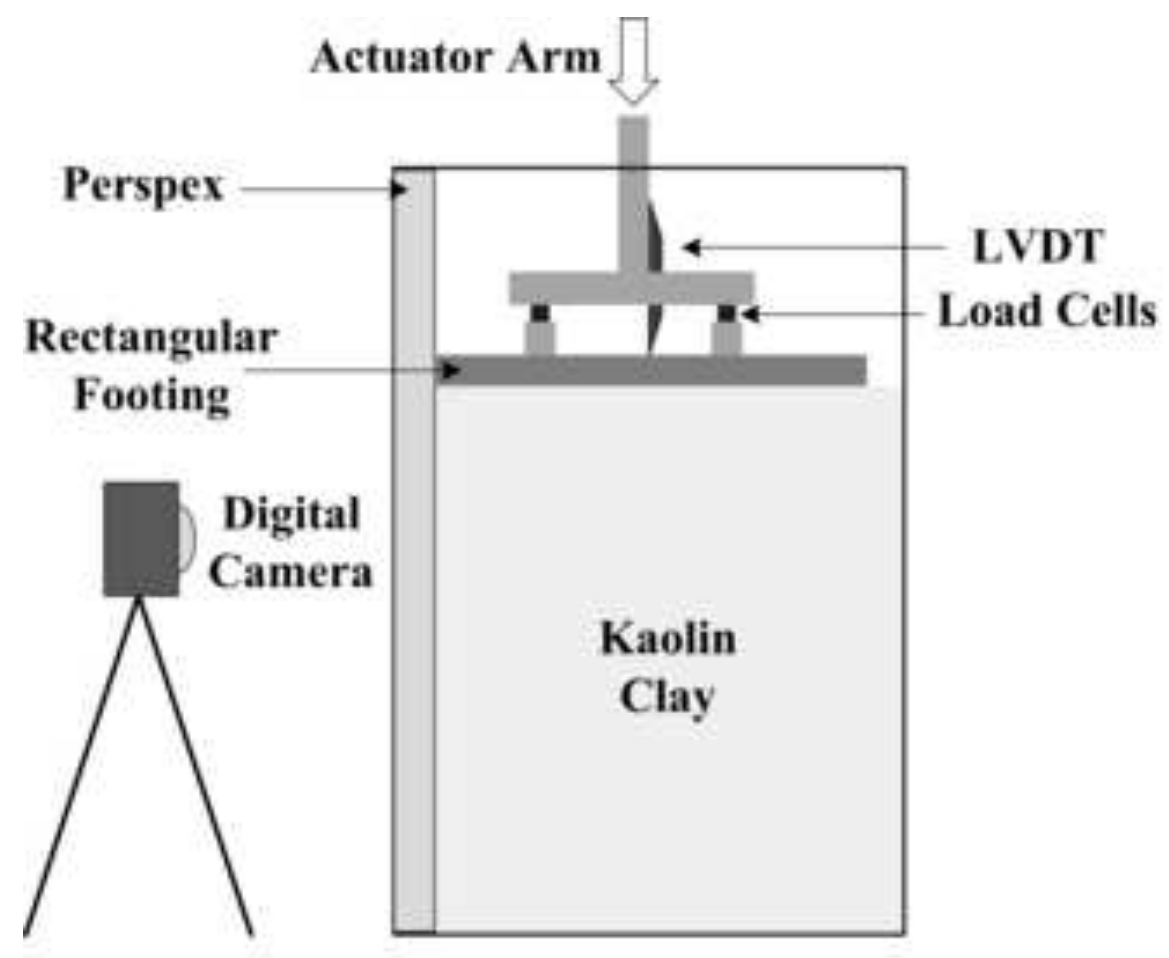

a) Schematic of experimental setup

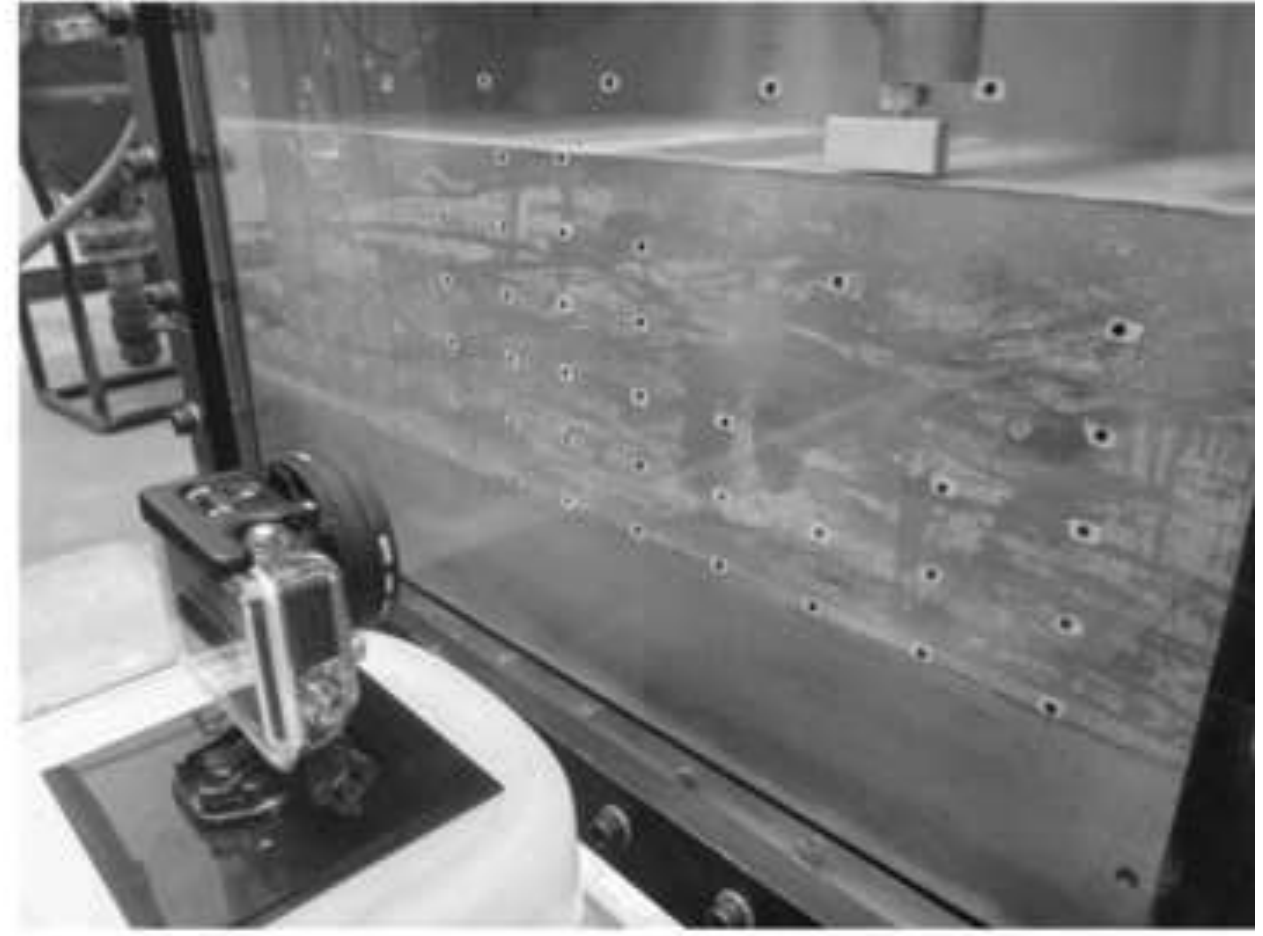

b) Photograph of experimental setup 


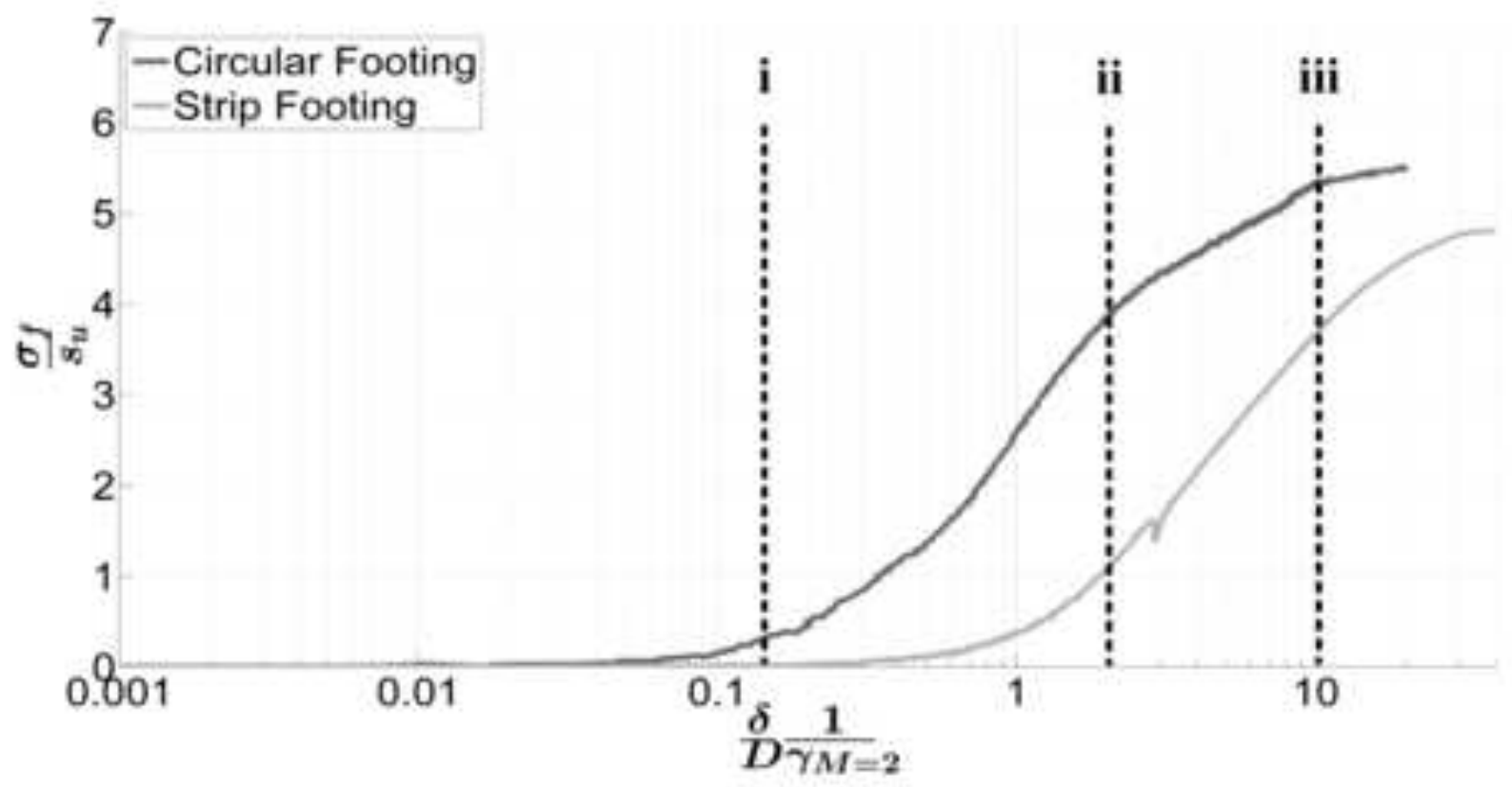

a) Measured Load Displacement
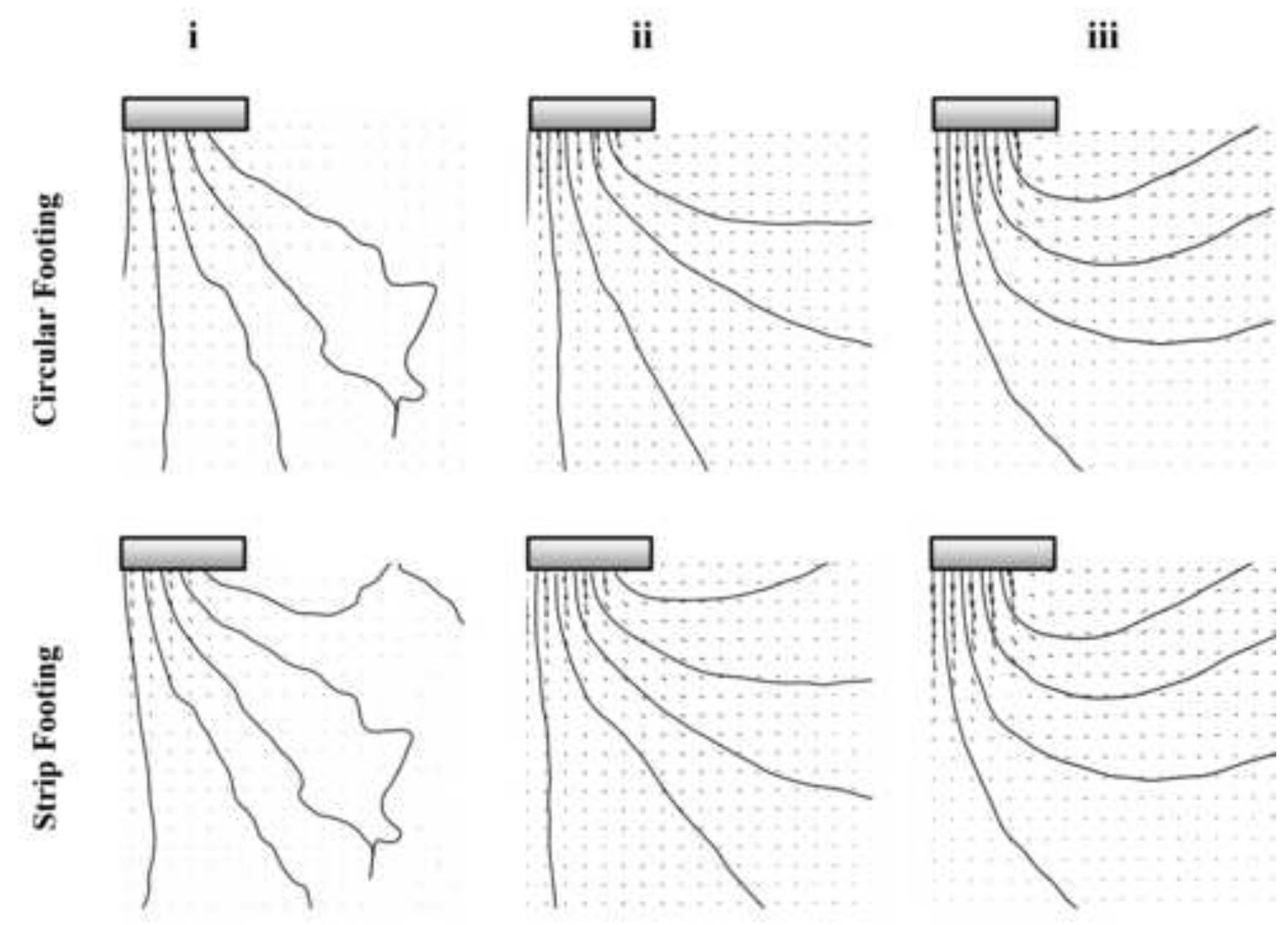

$=$ Footing 


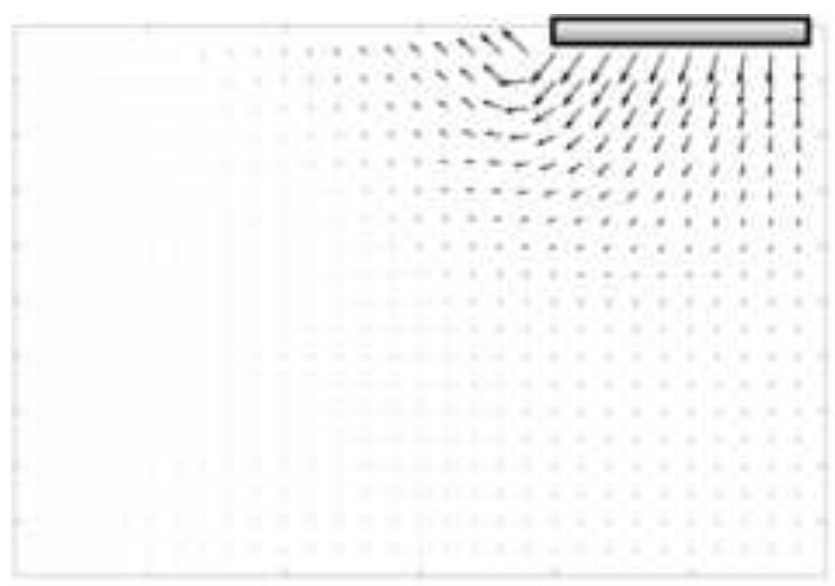

a) Deformation Mechanism
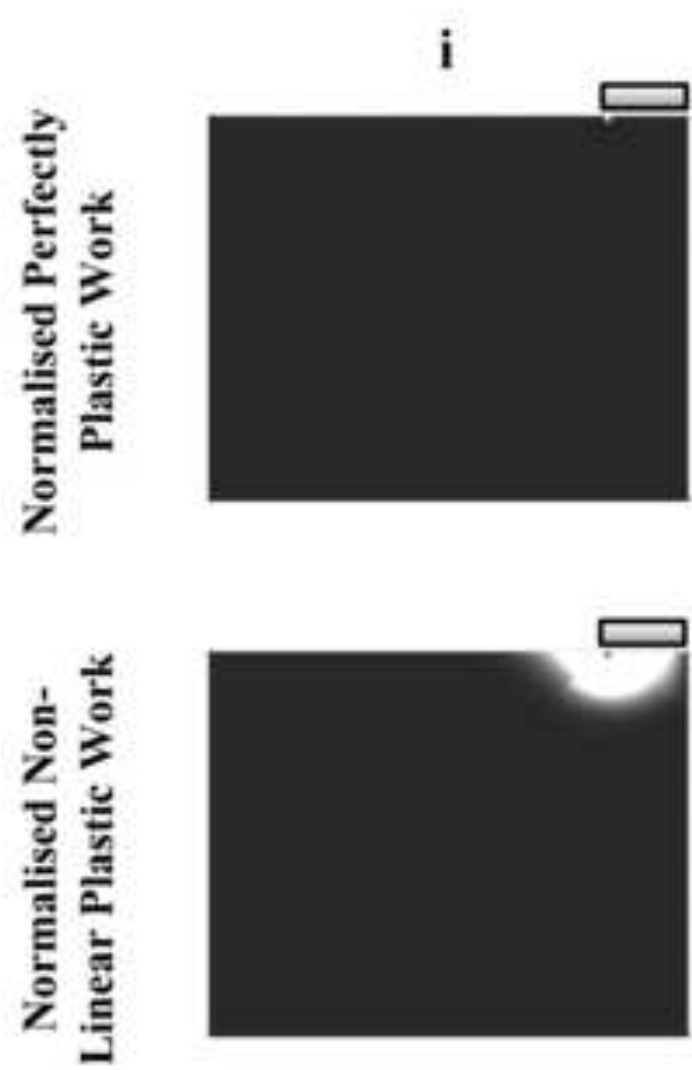

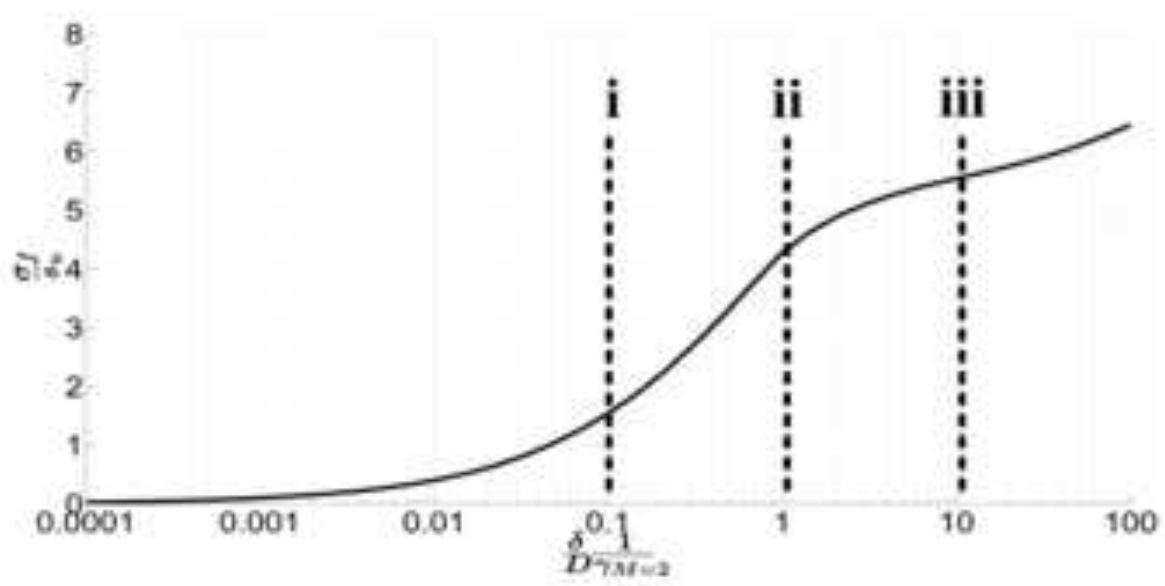

b) Predicted Load Displacement
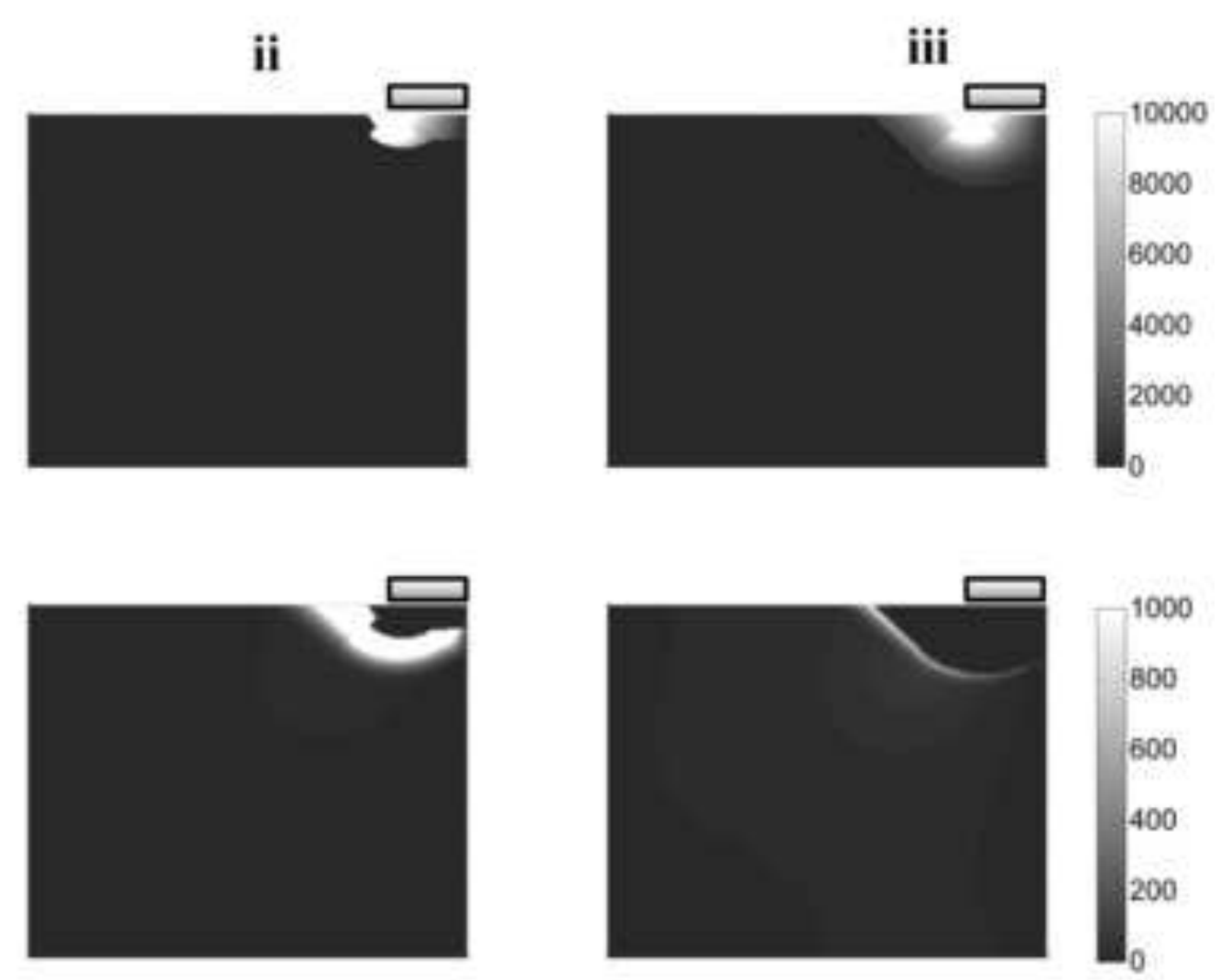

c) Energy Dissipated

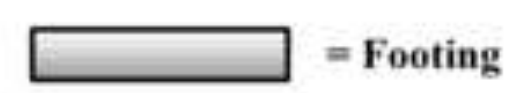


Figure 5a_b

Cligk here to otwnload Figure: figure5v2a_and_b.eps
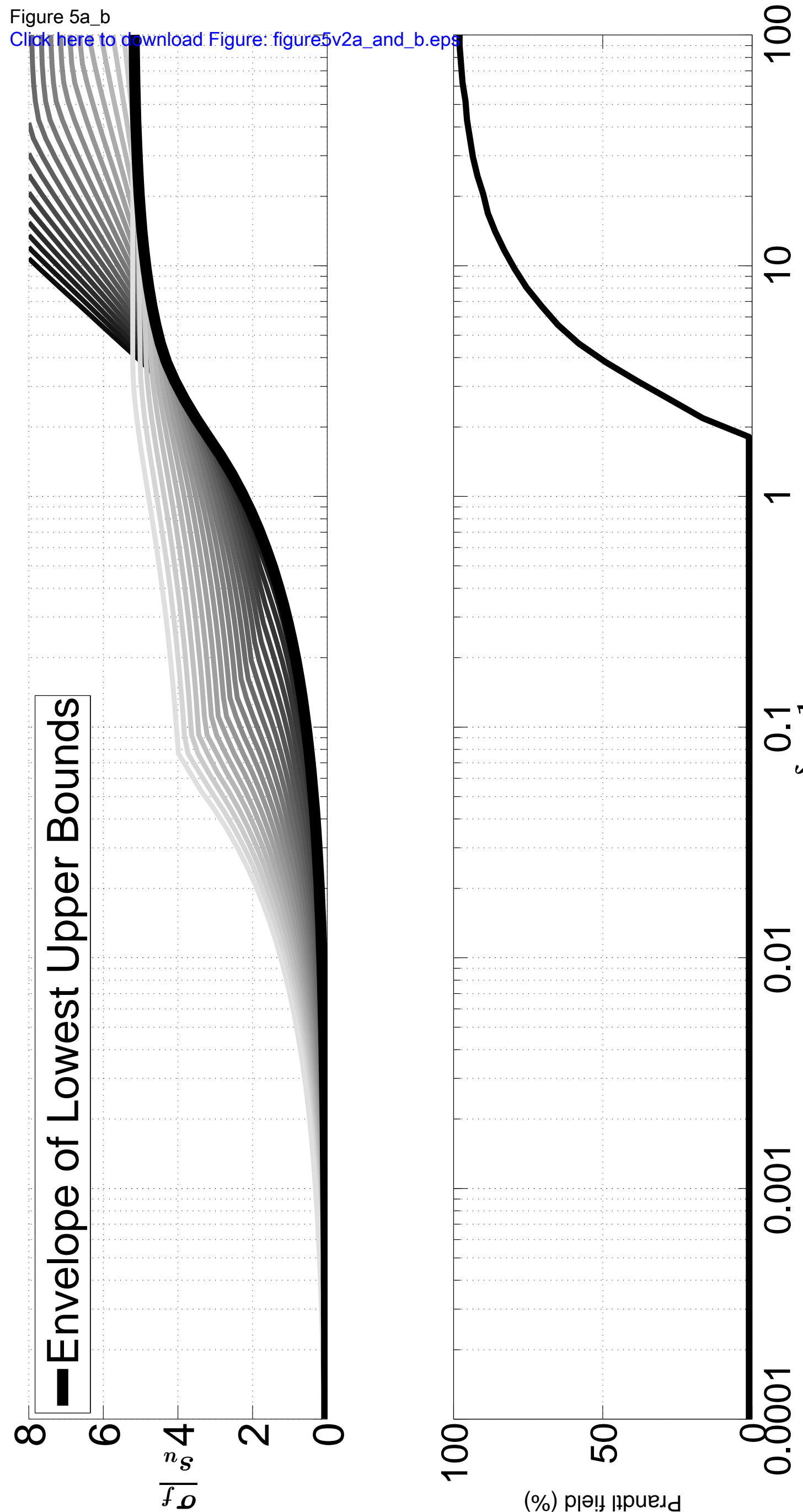

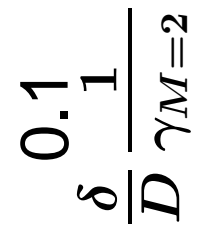

$\dot{0}$

5
0
0

(\%) p|ә!! ןpuedd 


\section{Figure 7}

Click here to downtoad Figure: figure7v2.eps

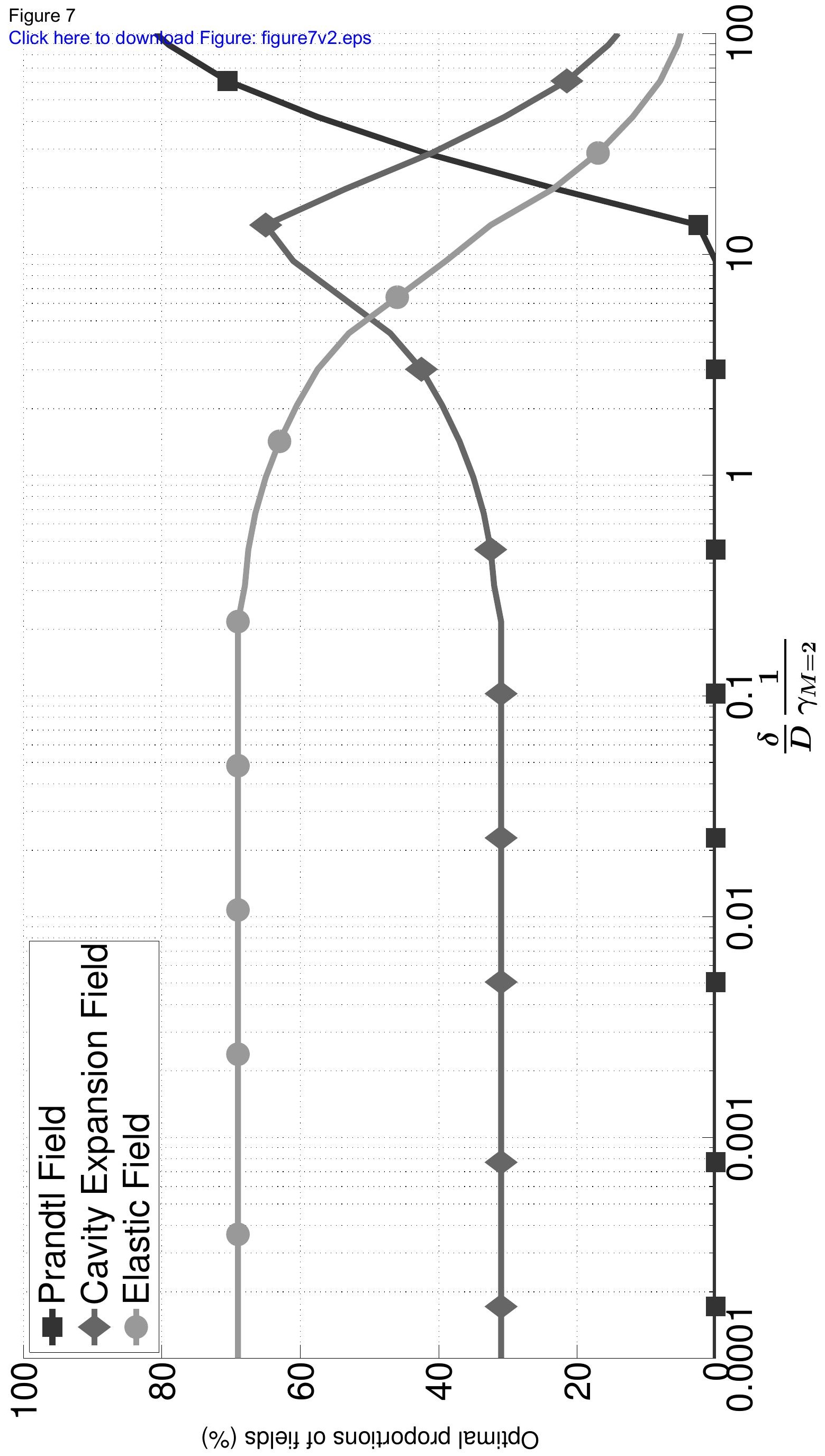

(\%) sp|ə!! to suo!̣ıodoıd ןem!̣do 
Click here to download Figure: Figure8v2.tif

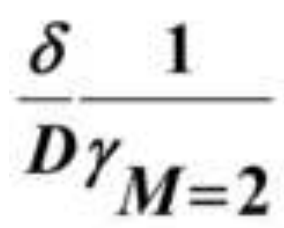

Theoretically
Predicted Optimal Field
Experimentally

Observed Field

0.1

1

10
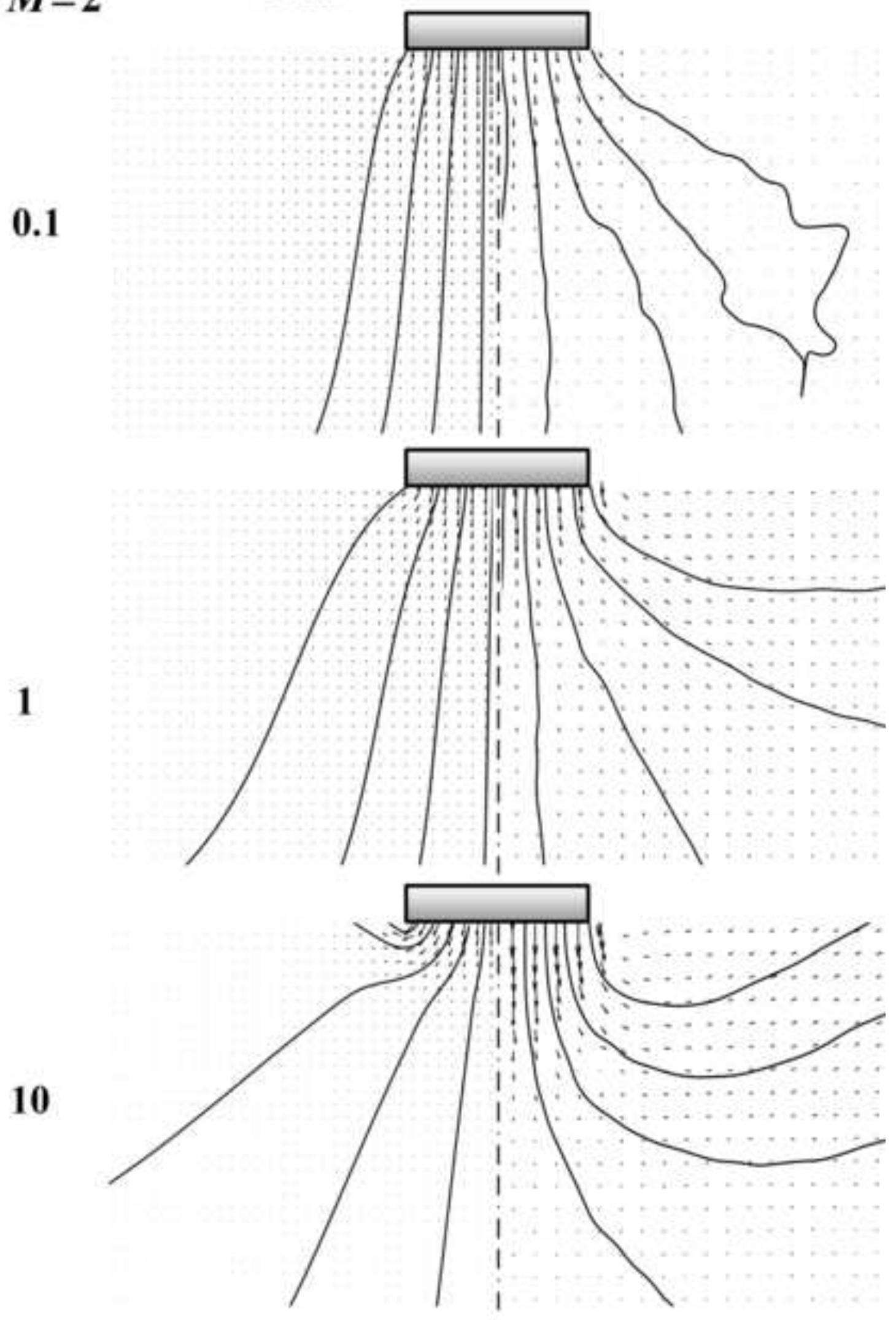
$=$ Circular Footing 


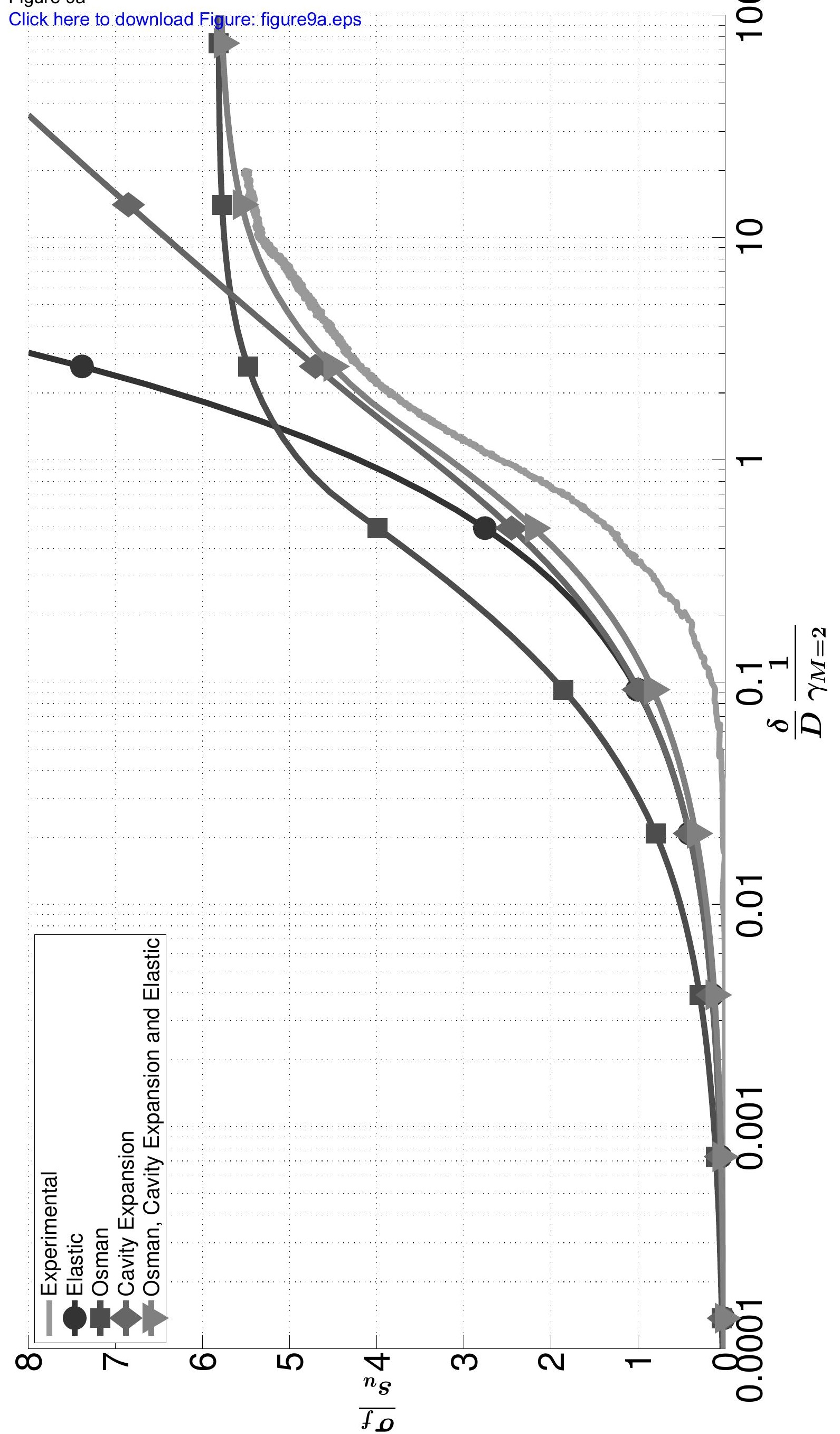


Figure $9 \mathrm{~b}$

Click here to download Figure: figure9b.eps

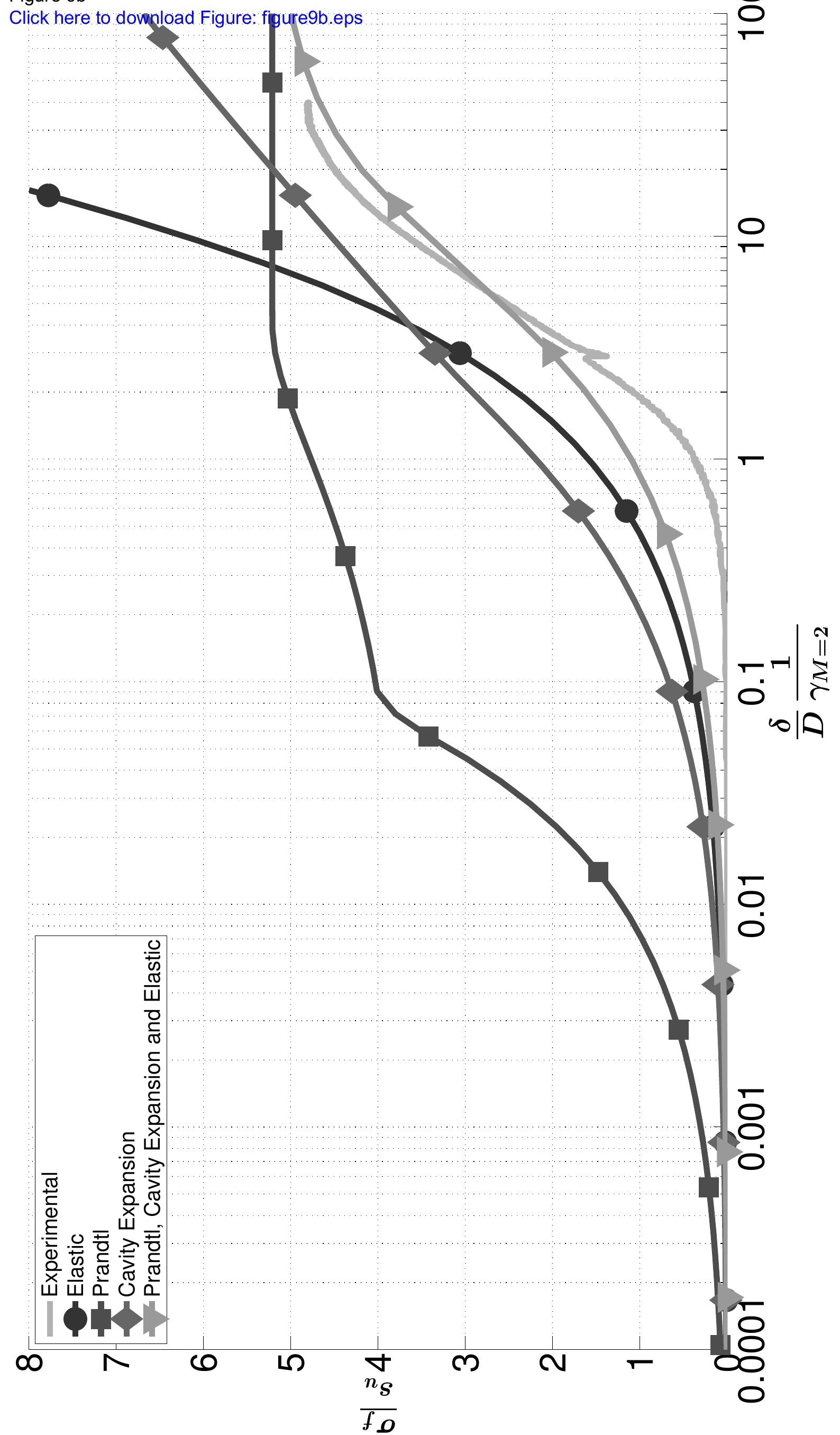

움

(1)


Figure 10

Click here to download Figure: Figure10.eps

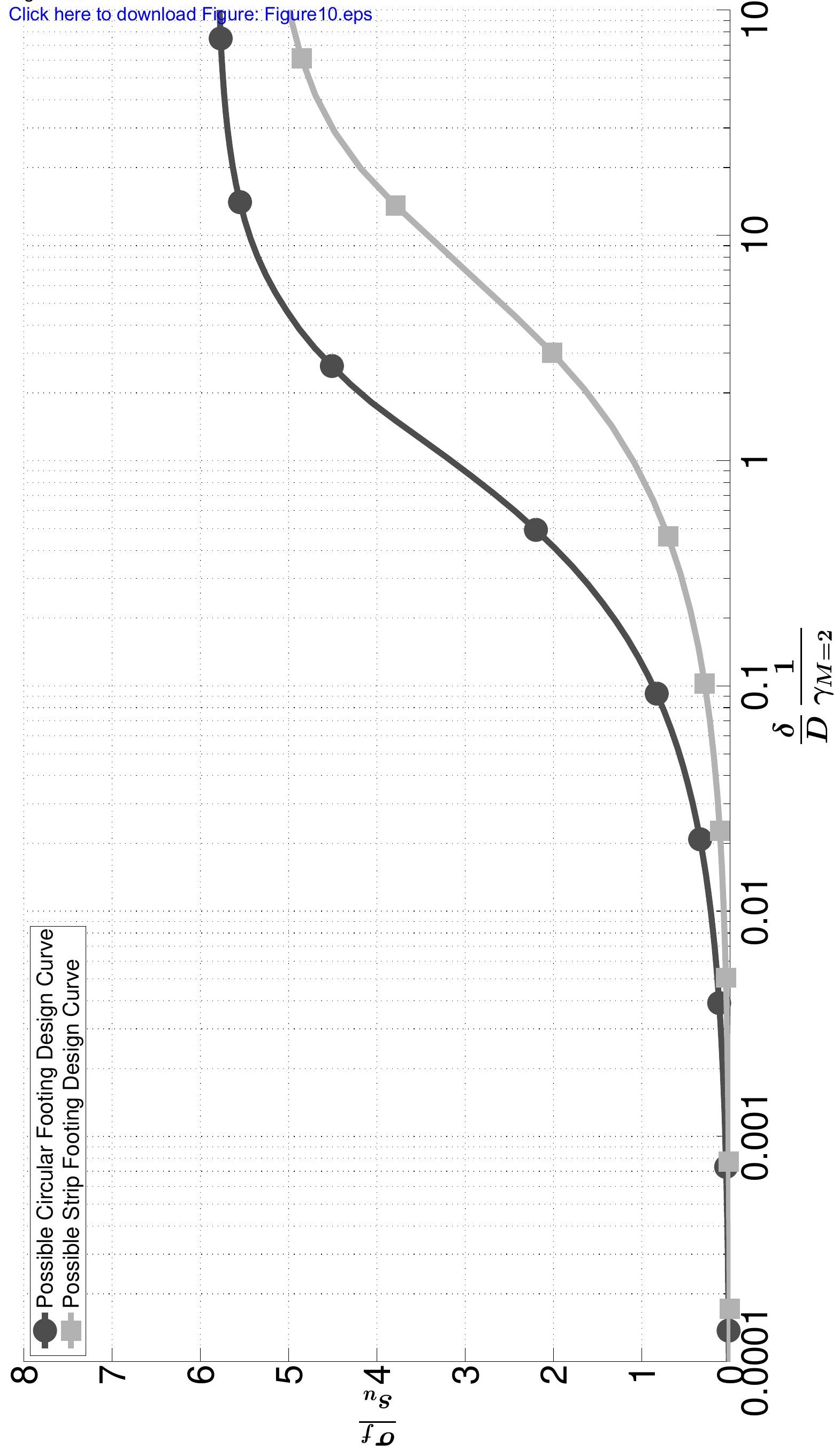


Table 1 Summary of test configurations

\begin{tabular}{|c|c|c|c|c|c|}
\hline \multirow[b]{2}{*}{ Test Id } & \multirow{2}{*}{$\begin{array}{l}\text { Type of } \\
\text { foundation }\end{array}$} & \multirow{2}{*}{$\begin{array}{c}\text { Nominal } \\
\mathrm{s}_{\mathrm{u}}(\mathrm{kPa})\end{array}$} & \multirow[b]{2}{*}{ Type of test } & \multicolumn{2}{|c|}{ Soil Characterisation } \\
\hline & & & & $\begin{array}{l}\text { No. of Vane } \\
\text { shear tests }\end{array}$ & $\begin{array}{l}\text { Samples for U- } \\
\text { U Triaxial test }\end{array}$ \\
\hline MSC1-a & Strip & 25 & Plane strain & & \\
\hline MSC1-b & Semi-circular & 25 & Axisymmetric & 8 & 2 \\
\hline MSC1-c & Semi-circular & 25 & Axisymmetric & & \\
\hline MSC2-a & Strip & 50 & Plane strain & & \\
\hline MSC2-b & Semi-circular & 50 & Axisymmetric & 16 & 2 \\
\hline MSC2-c & Semi-circular & 50 & Axisymmetric & & \\
\hline MSC3-a & Strip & 100 & Plane strain & & \\
\hline MSC3-b & Strip & 100 & Plane strain & 16 & 2 \\
\hline MSC3-c & Semi-circular & 100 & Axisymmetric & & \\
\hline
\end{tabular}


Table 2 Summary of soil characterisation results used to normalise load-settlement behaviour

\begin{tabular}{cccc}
\hline Test Id & $\begin{array}{c}\text { Average of } \\
\text { measured } \mathbf{s}_{\mathbf{u}} \\
(\mathbf{k P a})\end{array}$ & $\begin{array}{c}\boldsymbol{\gamma}_{\boldsymbol{M}=\mathbf{2}} \text {, Shear } \\
\text { Strain at half } \\
\text { mobilised } \mathbf{s}_{\mathbf{u}}\end{array}$ & $\begin{array}{c}\text { b, empirical } \\
\text { exponent relating } \\
\frac{\boldsymbol{\tau}}{\boldsymbol{s}_{\mathbf{u}}} \text { to } \boldsymbol{\gamma}\end{array}$ \\
\hline MSC1 & 24.00 & 0.030 & 0.6431 \\
MSC2 & 34.00 & 0.015 & 0.8697 \\
MSC3 & 65.00 & 0.012 & 0.7488 \\
\hline
\end{tabular}


Table 1: Summary of test configurations

Table 2: Summary of soil characterisation results used to normalise load-settlement behaviour

Figure 1: Examples of deformation mechanisms, following from McMahon et al (2013a)

Figure 2: Experimental setup

Figure 3: Combining the load settlement behaviour with the experimentally observed deformation mechanisms obtained using the GeoPIV software

Figure 4: Upper bound load settlement prediction based on linear mix of $90 \%$ Osman and $10 \%$ Elastic solutions

Figure 5: Determining the envelope of lowest upper bounds by linear mixes of plane strain Prandtl and Elastic solutions

a) Envelope of Lowest Upper Bounds

b) Optimal Proportion of Prandtl Field

Figure 6: Determining the envelope of lowest upper bounds by linear mixes of axisymmetric Osman, Cavity Expansion and Elastic solutions

a) Envelope of Lowest Upper Bounds

b) Optimal Proportion of Fields

Figure 7: Optimal proportion of linear mixes of plane strain Prandtl, Cavity expansion and Elastic solutions

Figure 8: Determining the envelope of lowest upper bounds based on GeoPIV deformation fields

Figure 9: Comparison of theoretical and experimental load settlement behaviour

a) Circular Footing Predictions

b) Strip Footing Predictions

Figure 10: Possible design curves for predicting undrained settlement of circular or strip footings 


\section{Journal Publishing Agreement}

It is our policy to ask authors to assign the copyright of articles accepted for publication to the Publisher. Exceptions are possible for reasons of national rules or funding. Please tick the relevant options below.

In assigning copyright to us, you retain all proprietary rights including patent rights, and the right to make use of the article, subject to acknowledgement of the journal as the original source of publication.

By signing this agreement, you are confirming that you have obtained permission from any co-authors and advised them of this copyright transfer. Kindly note that copyright transfer is not applicable to authors who are opting to publish their papers as Open Access. Open Access authors retain copyright of their published paper.

Please complete the form below and return an electronic copy to your ICE Publishing contact (http://www.icevirtuallibrary.com/info/submit ).

Journal name:........eo techn!que

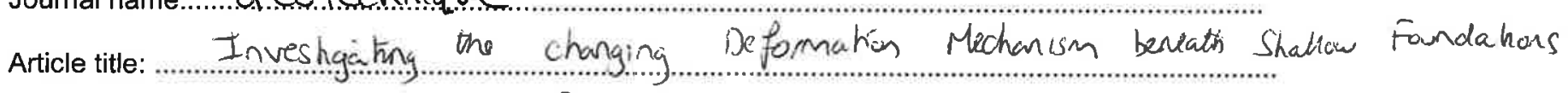

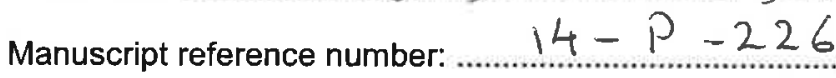

Authors: Mr... Srikanth S C Madabnushi Dr Stuat K Haigh

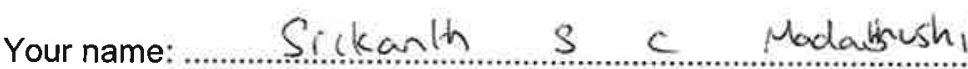

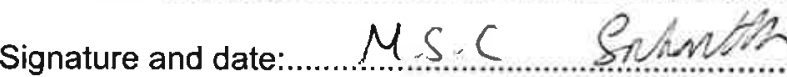

Please tick either one option from part A or one option from part B. Please complete part C

A. Copyright

I I hereby assign and transfer the copyright of this paper to Thomas Telford Ltd.

British Crown Copyright: I hereby assign a non-exclusive licence to publish to Thomas Telford Ltd.

$\square$ I am a US Government employee: employed by (name of agency)

$\square$ I am subject to the national rules of (country) ............................ and confirm that I meet their requirements for copyright transfer or reproduction (please delete as appropriate)

B. Authors with open access funding requirements. Please specify the Creative Commons license version required.

CC-BY (for full details click here Creative Commons Attribution (CC BY) 4.0 International License)

CC-BY-NC-ND (for full details click here Creative Commons Attribution Non Commercial No-derivatives (CC BY NC ND) 4.0 international License)

C. Please confirm that you have obtained permission from the original copyright holder. For ICE Publishing's copyright policy, please click here. ICE Publishing is a signatory to the STM Guidelines

7 I have obtained permission from the original copyright holder for the use of all subsidiary material included in this paper (E.g. for borrowed figures or tables).

Thomas Telford Ltd is wholly owned by the Institution of Civil Engineers

Telephone: +44 (0)20 76652242 | Fax: +44 (0)20 7665 2189 |Web: www.icevirtuallibrary.com 


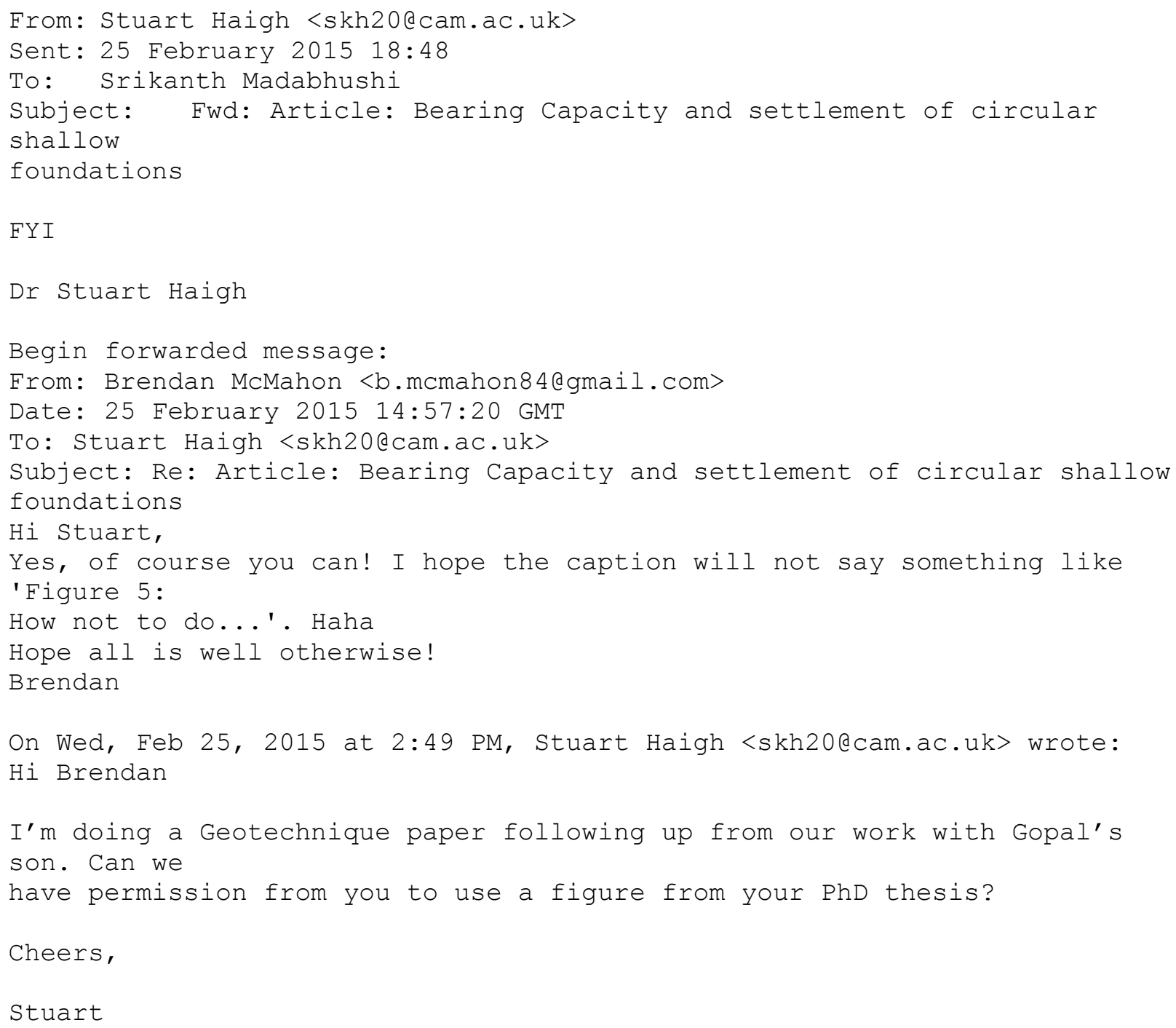

